\title{
Never Smile at a Crocodile: A bad Viva Voce by the rule book
}

\author{
Dan Remenyi \\ Extraordinary Professor, University of the Western Cape \\ dan.remenyi@academic-publishing.org \\ DOI: 10.34190/JBRM.17.2.02
}

\begin{abstract}
This is a narrative, the objective of which is to open a conversation about some aspects of how doctoral degrees are examined. The focus here is on a viva voce which was conducted for a mature candidate who had been registered for his doctorate for some 10 years and who came close to failing this examination.
\end{abstract}

\begin{abstract}
The narrative presented is a description of a viva voce examination which was conducted by the rule book and resulted in what is described here as an outcome which the degree candidate and his supervisors regarded as unfortunate. There was no misconduct on the part of anyone but some mistakes were made by the degree candidate during the examination in that the candidate did not answer well the questions put to him and the examiners did not attempt to correct him or assist him with his nervousness, which was quite apparent. As a result, the candidate's examination performance was regarded by all to be poor.
\end{abstract}

The problem which caused this unfortunate event, it is argued, lay in the lack of concentration on the part of the degree candidate and the absence of what John Maynard Keynes once referred to as the goodwill of the examiners, which was in short supply (Checkland, 1981). This narrative and the accompanying reflections reveal how delicate the viva voce process actually is and why in its current form it may need a thorough review. The paper concludes with the suggestion that the viva voce needs reform.

Keywords: Viva voce examinations, the Defence, examination goodwill, viva voce reform, examination bias, rewriting dissertations

\section{Introduction}

This paper is an account of one viva voce examination for a doctorate degree. The outcome of this examination was considered unsatisfactory by the degree candidate and by his two supervisors who were present at the examination. The viva voce examination, or the Defence as it is called the USA, is often described in the literature in positive terms (Remenyi et al. 2003). Many doctoral degree candidates have a constructive experience in defending their doctoral research and it has been argued that a viva voce examination should be as much a learning experience as an examination. However, this paper reveals that this view may be unduly optimistic as viva voce examinations can go wrong even when they are being implemented according to the rule book. Different concerns have been raised by others about the viva ( Tinkler and Jackson, 2000; Wolensky, 1979).

\section{The background to this viva voce examination}

The background to this viva voce examination is important. The degree candidate was a mature individual who already had a senior appointment at another university. He had been registered for his doctorate for more than 10 years during which time there had been many reasons offered for the delay in finalising the dissertation. Both the supervisors had found this frustrating and were anxious that this degree be concluded.

In the view of the supervisors the dissertation was not perfect and probably needed additional work ${ }^{1}$. The amount of additional work required was not necessarily trivial, but on the other hand the dissertation had a number of good qualities and it did not require a substantial rewrite. The evaluation of the dissertation rested on a fine line between whether the work required minor amendments or major amendments, but this was not reflected in the outcome of the viva voce examination. The degree candidate did not make any specific preparations for the viva voce in that he did not request a mock viva (Murray, 2003).

\footnotetext{
${ }^{1}$ It could be argued that the degree candidate should not have been allowed to go forward for examination at this point. However, he was desirous to so do and the supervisors were of the view that they were reaching an exhaustion point with regards to being able to offer him any further help in his intellectual development.
} 


\section{Who attended the examination?}

The viva examination was attended by the Director of the doctoral degree programme who was in the Chair, one external and one internal examiner and with the consent of the two examiners, the degree candidate's two supervisors. The presence of the two supervisors was allowed subject to their not making any comment during the examination. Strict silence on the part of the supervisors is the rule on these occasions and this was carefully observed.

Both examiners were experienced as doctoral supervisors and examiners. One examiner had more than 30 years experience and the other had about 15 years. The Director of the degree programme was also an experienced academic with about 3 years in his position, and who received his doctorate about 12 years before. For completeness it should be pointed out that the two supervisors had about 60 years of academic experience between them - one supervisor had 40 years experience while the other had 20 years experience. Clearly the experience of the examiners is important, but more than experience is required of examiners if the viva voce is to deliver a fair outcome for the degree candidate.

The British viva - or to use the USA term, Defence - is held in private. In continental Europe this examination process is sometimes held in public (Kyvik, 2014) ${ }^{2}$.

The viva was held in a small seminar room. This room made the atmosphere more intimate than would have been the case with other venues. In retrospect it could be argued that the room was too small and that it made the event appear cosy as one might experience with a small group seminar. The event was of course, not a seminar. It was an examination with all the implications which accompany this type of affair.

\section{Examination advice to the candidate}

The candidate had been given very specific instructions about how to handle himself during the examination. He was told to concentrate on the questions to which he had to listen carefully. He was told to curtail his answers, where possible, to two or three minutes. In cases where he had more to say he was advised to ask the examiners if his explanation was adequate or whether they would like him to further expand on the issues involved.

\section{The examination}

The examination commenced at the scheduled time with the Chairperson welcoming everyone and ensuring that they all knew who everyone was. He went on to state that the examiners would be posing questions to the degree candidate, and that this would commence as soon as he handed the event over to the external examiner. There was no comment made concerning the standard which would be required from the degree candidate (Murray, 2003). Following this introduction the external examiner was asked to take over control of the meeting and begin with the initial questioning.

Before the first question was asked the degree candidate said that he had prepared a short presentation about the research and suggested that he speak to this. Perhaps surprisingly the examiners declined this offer. In retrospect it was a mistake for the candidate not to make a clear statement as to what he believed his dissertation constituted as a contribution to his field of study.

The opening questions were exactly what one would expect, such as: What do you consider to be the importance of this subject area? Why did you want to research this topic? The candidate's replies to these were competent, and unexceptional. Then a question asking for a definition of the central concepts being studied was posed. This surprised the candidate and he was not able to give a satisfactory answer. The candidate pointed out that there were many different ways of defining these concepts and did not make any further substantive comment on this. This was certainly disappointing. In fact this was the candidate's first

\footnotetext{
${ }^{2}$ In Sweden for example this examination is open to anyone who wishes to attend and any member of the public may ask any questions they wish. This can lead to a situation where an individual who has a grievance against a degree candidate can by asking demanding questions attempt to embarrass the candidate in public. There is no strict time limit to this examination in Sweden. In the Netherlands the equivalent examination is also open to the public but only questions submitted in writing from individuals who already hold a doctorate degree will be accepted and put to the degree candidate. There is a strict one hour limit on this examination in the Netherlands. The Dutch version of this examination is much more formal than the Swedish and this formality is increased by the fact that all those involved need to be dressed in full academic attire.
} 
step on the road to coming close to failing his viva. The examiners moved on to the next question and at that point nothing further was made of this critical definition issue.

The examination proceeded for another two hours during which time a wide range of issues were addressed. As an observer I was fully aware that the degree candidate did not answer a number of these questions to the satisfaction of the examiners.

After approximately two hours the Chairperson called for a comfort break, which lasted for about 10 minutes and then the examination resumed for about another 30 minutes.

\subsection{The candidate's conduct during the examination}

In general, the viva did not go well. The candidate was shown not to have been as careful with some aspects of his research as he could have been. When the examiners identified a problem in the way the dissertation had been developed they then moved on to their next question. There was very little feedback given so the candidate was not aware of what the examiners considered to be important or minor flaws. In fact, the examiners neither complimented the candidate when he replied well nor were they critical when his replies were inadequate. This meant that the candidate did not know how well or how poorly he was doing.

What made his problem worse was that after the first hour the candidate began to feel more relaxed and he seemed to forget ${ }^{3}$ the instructions with regards to how he should answer the questions. He started to give long-winded answers. At one point he chattered on to the extent of anticipating what the examiners' next question might be and then he answered it. He offered gratuitously a number of remarks which he should under no circumstances have made, including stating that he could have, during the data collection phase of his research, conducted another case study. He simply dropped his intellectual guard completely.

In effect, the doctoral degree candidate lost attention on what he was doing and began to think that he was having some sort of a jolly conversation with friends instead of being examined.

The supervisors sat silently through what was obviously a deteriorating situation.

\subsection{A question without prior notice}

The examination ended with what can only be described as a very difficult question from the internal examiner, during which the candidate completely missed the point and gave an inappropriate answer. The question was approximately: -

Returning to your literature review, choose two or three authors with whom you are familiar. Taking the findings of your research express for each of these authors how your findings have been able to enrich or enlarge these published authors' contribution to your field of study. If you cannot find examples of how other researchers work could be impacted positively by your own, then find examples of how the work of other researchers could have their scope redefined or reduced by your research.

There is no doubt that this is a non-trivial question (Chen, 2014). It goes to the very heart of academic research and focuses on the nature of the theoretical contribution of the candidate's work. It is not clear how many doctoral degree candidates could provide a satisfactory answer to this question. Some academics might even argue that it is too demanding to be asked of anyone without appropriate prior notice.

\subsection{The candidate missed the point of this question.}

At this juncture the Chairperson announced that the question and answer part of the viva voce was over and that the two supervisors and the candidate should go to lunch together. He and the examiners would stay behind to discuss the result of the examination and then go to lunch separately. The formal proceedings would reconvene in one hour's time.

\footnotetext{
${ }^{3}$ The word "forget" is used as a charitable interpretation of the candidates' motives. What happened was that he did not comply with the suggestions made to him about how to answer questions during a viva.
} 
The candidate was not asked to make a final statement about how he now felt, as a result of the discussions, about his contribution to his field of study.

\section{Discussion over lunch}

Lunch was a relatively subdued if not actually tense affair. Over the meal, the candidate expressed the fact that he felt that the viva had gone well. He pointed out that the body language of the examiners had been positive. He felt that he had learnt from the experience. He was quite upbeat about what had just happen during the examination. The supervisors had trouble in communicating their reservations and the candidate's shortcomings. However, it was pointed out that the fact that the candidate had not been able to offer a satisfactory definition of some of the basic concepts in his field of study was a serious shortcoming.

The candidate was told by his supervisors that some of the answers were too long and that he completely missed the issue of the last question put to him. On completing lunch the supervisors met up with the Chairperson and the examiners when they were coming out of the examination room. They had taken the whole hour to decide what they would say to the candidate. The Chairperson said that the reconvening of the examination would commence a half hour later than originally planned.

\section{The result of the viva}

This delay in the restart of the viva represented the fact that the examiners had much to say to each other about the candidate's dissertation and viva performance and this produced a substantial list of corrections to be made. What they asked the candidate to do can be summarised as rewriting a major part of the dissertation. It could be regarded as one step away from a fail. The negative effect this had on the degree candidate was palpable (Carter and Whittaker, 2009).

There was good reason given for these requirements and in general it would not be proper to question the academic judgements involved ${ }^{4}$. However, what can be said is that the candidate did not take the advice given to him concerning how to answer the questions. He lost focus on the fact that he was being examined and that his detailed performance was being carefully watched. Because the examiners did not point out his inadequate answers or contradict his remarks, but had shown positive body language, this was interpreted by him that he was doing well.

The reason that this narrative is called "Never smile at a crocodile" is that all doctoral degree candidates need to realise that no matter how pleasant, affable or warm the examiners appear, they are always examiners and the candidates' intellectual guard should never be relaxed until the results of the examination are declared. Like the words of the song from Peter Pan, which describes a suitable relationship with a crocodile, a smile from an examiner means nothing.

It could be argued that the examiners silence when the candidate gave poor or mistaken answers to their questions was misleading.

\section{Fairness and the doctoral examination}

On a broader level there is concern about the intrinsic fairness of a doctoral examination. First of all, the doctoral candidate who may not yet have fully cut his/her teeth as a researcher is asked to face the scrutiny of two experienced researchers. In this case the two examiners had about 45 years research experience between them. This is clearly an unbalanced situation ${ }^{5}$ and it calls at least for what John Maynard Keynes referred to as goodwill on the part of the examiners. Peter Checkland (1988) in his book Systems thinking, systems practice recounts a story he attributes to Keynes concerning how Keynes' rival Friedrich Hayek criticised the famous book Treatise on money. Keynes' riposte to Hayek's remarks was: -

\footnotetext{
${ }^{4}$ It is continually asserted that the academic judgement of the examiners at a viva voce cannot be questioned. It is clear that universities do not like having any academic decision questioned but it is also true that mistakes are sometimes made. I have encountered a large range of mistakes in the years I have been involved in academe, ranging from addition mistakes on the cover of an exam book to a Professor grading a script from another part of the examination in which he had no involvement, and no knowledge of the subject he had graded. I wonder if the belief that the academic judgement of the examiners cannot be questioned is derived from the same thinking that asserts that the Pope is infallible. The early universities came out of cathedral schools and even today there are echoes of the ecclesiastic world in some parts of university procedures.

${ }^{5}$ I feel sure that a viva should never be a contest between examiners and the degree candidate but it is a challenge to make sure that no element of contest comes into this event.
} 
Hayek has not read my book with that measure of "goodwill" which an author is entitled to expect of a reader. Until he does so he will not know what I mean or whether I am right.

It is not possible to identify any goodwill in this viva voce examination. Had there been goodwill leading to some degree of balance it would have led to some of the better points of the dissertation being raised and discussed. But this did not happen.

\section{The role of the Chairperson}

The role of the Chairperson is often defined as someone who needs to be satisfied that the two examiners had spent a considerable amount of time reading the dissertation and preparing for the viva in advance ${ }^{6}$; that the time allocated for the examination was fair and that the degree candidate was not pressurised or rushed and that the questions were put in a reasonable manner. With this examination the Chairperson felt that the examiners had taken the candidates' viva comments into account in coming to their final decision. And finally the Chairperson stated that he believed that the examiners were both in agreement with the final outcome of the research.

It is perhaps not clear that this is a satisfactory definition of the role of a Chairperson. What appeared to happen in this examination was that the examiners focused on what was not in the dissertation and had hardly mentioned what was in the dissertation. This is perhaps a reflection of insufficient "goodwill". Would it not improve the viva examination process if the Chairperson was tasked with ensuring that both the strengths and the weaknesses of the dissertation were aired during the questions and answers session?

\section{What is the standard of a particular university?}

Another issue that raised its head as a result of this event was that of how a university can ensure a consistent standard with regards to its research degrees. There are a number of different aspects to this including that the external examiner appointed is not expected to be too close to the university. It is important that external examiners are not too familiar in the sense of being "friendly" or well disposed to the institution for which they are acting as an external. While there is a good reason for this, the external may not be adequately familiar, in the sense of knowledgeable about the standard required by that institution. There is actually an unspoken assumption that doctorates from all universities will be of the same standard which is, of course, not correct (Morley, Leonard and David, 2002). The term Republic of Scholars (Brubacher, 1967) suggests equality among scholars and universities which does not stand up to any competent scrutiny. Differences between universities in respect of scholarship and standards appear to be rife as are differences within universities from Faculty to Faculty or School to School.

The question of determining the standard of doctoral work within a particular university or faculty is easily addressed. It is common practice for universities to publically display the standard for their research degrees in so far as it makes completed dissertations available in the library. All that has to be done to establish the standard is to spend some time in the library. Libraries can be quite difficult when it comes to lending PhDs for fear of plagiarism but these books are readily available for reading in the confines of the library itself. Furthermore many dissertations are now available for purchase on the web ${ }^{7}$. But it takes time to read these and examiners are not adequately recompensed for the work they currently do, never mind having to read several more dissertations to become familiar with the particular standards of the institution where they are examining $^{8}$. The current assumption that all dissertations are of the same standard is certainly an issue that needs addressing.

In addition to the external examiner's understanding of the standards question there is the difficulty which may be presented sometimes by the internal examiner who may be friendly or antagonistic towards the

\footnotetext{
${ }^{6}$ This, of course, implies that the Chairperson will have read the dissertation in full and this may not actually be the case.

${ }^{7}$ See http://www.theses.com/. This website claims to have available theses for which higher degrees have been awarded in the United Kingdom and Ireland since 1716.

${ }^{8}$ The fee paid for the examination of doctorates is in most cases derisory. The fee is below the national minimum wage. The rationale for this is unclear. The examination of research dissertations is of considerable import which is not recognised by the universities. Examiners are often recruited on an informal reciprocity basis which is that if someone examines for you, you will one day examine for him or for her. Allowing examinations to be conducted by examiners selected on this type of basis is highly questionable.
} 
degree candidate. How do universities ensure the impartiality of their internal examiners? The internal may not have had good experiences in their contact with the degree candidate or the supervisors and this may colour their perceptions of the work being examined. On the other hand the internal may feel that the degree candidate is better than he or she actually is and there may be a bias in favour of the person being examined ${ }^{9}$. The bias of the internal examiner may be at either a conscious or unconscious level. Being perfectly impartial is something all academics strive for, but researchers know that it is usually not possible to eliminate all the bias that we all carry with us. Complete impartiality is at best a fanciful delusion. At worst it is a deliberate falsehood.

This problem is exacerbated by the fact that some universities do not have adequately qualified and experienced staff to undertake this internal examiner role.

\section{The nature of the changes required}

The final matter is the nature of the changes which examiners offer the candidate in order to improve the dissertation. It is often quite difficult to express in a clear, succinct and unambiguous way what is actually required. As a result comments like "Revisit the substantive content of the literature and produce a more comprehensive synthesis in order to provide a richer context for subsequent analysis" and/or "Use more sophisticated approaches to the analysis of his interview data further to exploit the richness of the data and to augment his existing work on counting terms by themes ${ }^{10 "}$ are sometimes made. It is difficult to translate these words into a course of meaningful action. There is no suggestion of deliberate obfuscation here. Except for trivial problems, it is remarkably difficult to give instructions as to what is required to improve the dissertation. But without clear, succinct and unambiguous instructions it is difficult to know how the degree candidate can move forward and be awarded the degree.

The immediate examiners report is therefore the first step in providing instructions to the candidate as to how to improve his or her work. This may need to be followed with a full set of detailed instructions. Even then there may be problems in understanding the requirements and in the incident described here the degree candidate needed to have a personal meeting with the internal examiner in order to have some points clarified.

It is worth pointing out that the examiners did not call for a new viva voce which it was their prerogative so to do.

\section{Some reflections}

It is probably the case that the degree candidate was not ready for examination. Whether it was possible to have helped prepare him further, after a 10 year registration period, is not clear. Although the viva voce did not go well and there was an extensive period of rewriting to be done over the following 15 or 18 months, the candidate was eventually awarded a doctorate. Thus in a sense this degree experience may be regarded as having ended favourably, although hardly in an elegant fashion.

This narrative illustrates some of the dilemmas which are inherent in the viva voce process. As doctorates are the highest awards that a university can bestow it is not surprising that the candidate's examination is challenging. If asked the question "When will the university award me my doctorate?" the most satisfactory reply is, "You will be awarded your doctorate when the university is confident that you won't embarrass them". This, of course, is a rather high level answer and thus needs some fleshing out. Confidence has to be created by the candidate in terms of what is written in the dissertation and how is it defended during the viva. But there is no standard articulated as to at what level of skill is required (McAdams and Robertson, 2012). There is no place in a viva for a friendly exchange of views. It is first and foremost an examination and this means that it is a vehicle for judgement. A doctoral viva needs to be assessed by whether it is fair, transparent and consistent (Park, 2003).

\footnotetext{
${ }^{9}$ The most obvious example of this bias I have encountered occurred when I was an external examiner at a well known university. I arrived at the reception where I was greeted by the Dean of the Faculty, who told me he was the internal examiner for the viva I had agreed to examine. He then said that he had found the candidates work very interesting and potentially useful.

${ }^{10}$ These comments have been extracted from examiners' reports.
} 
In some cases, the viva can also be a learning experience for the degree candidate. But if this turns out to be so it is serendipitous. In the event described here the relaxed manner of the candidate which is described as the equivalent of smiling at a crocodile was inappropriate and led to confusion which perplexed the candidate.

And there is another lesson for degree candidates that can be taken from this viva experience, which is perhaps that the degree candidate should not present himself or herself in a totally passive manner to await questioning by the examiners. The degree candidate needs to ensure that the strengths of the dissertation are discussed. In some universities five to ten minutes are set aside at the start of the examination for the degree candidate to describe what has been done and what the outcome has been. This is the equivalent of a verbal abstract. But where this is not the established custom then it is important that the degree candidate presses the Chairperson to be allowed to do this.

The degree candidate should also sum up the discussion held during the viva. A list of the strong points he or she made would be a useful reminder to the examiners.

This narrative points to the need to reconsider, inter alia, the role of the Chairperson in the viva. A more active Chairperson can produce a more balanced event. It may also point to the need for more forthright feedback to the candidate during the examination itself. In addition, this case also questions the need for examiners to acquaint themselves with the standard of the institution where they are examining.

There is no doubt that the examination described above complied with all the university's rules and regulations and as such was flawless in execution ${ }^{11}$. Nothing occurred which could be construed to be inappropriate although the Chairperson perhaps played far too passive a role. The Chairperson is not there for decoration only. He or she has a quite specific role to play which was omitted in the situation described here. He could have compensated to some extent for the absence of "goodwill".

The question which remains is not "Do we need to review the process of the viva voce and especially the role of the Chairperson?" but rather "Why has the viva voce process not being overhauled some years ago?"

\section{References}

Brubacher, J., 1967. The autonomy of the university; how independent is the Republic of Scholars? Journal of Higher Education, 38(5,) pp. 237-249

Carter, B. and Whittaker, K, 2009. Examining the British PhD viva: opening new doors or scarring for life? Contemporary Nurse, 32(1-2), pp. 169-178

Checkland, P., 1981 Systems thinking, systems practice. Chichester: John Wiley \& Sons

Chen, S., 2014. Balancing knowing and not-knowing: an exploration of doctoral candidates' performance of researcher selves in the dissertation defence. Assessment and Evaluation in Higher Education, 39(3,) pp. 364-379

Kyvik, S, 2014. Assessment procedures of Norwegian PhD theses as viewed by examiners from the USA, the UK and Sweden, Assessment \& Evaluation in Higher Education 39(2), pp. 140-153

McAdams, C. and Robertson, D., 2012. An informed look at doctoral vivas (oral examinations) in the preparation of counselor educators, Counselor Education and Supervision, [e-journal] 51(3), https://doi.org/10.1002/j.15566978.2012.00013.x

Morley, L., Leonard, D. and David, M., 2002. Variations in vivas: quality and equality in British PhD assessments, Studies in Higher Education, 27(3), pp. 263-273

Murray, R, 2003. Students' questions and their implications for the viva. Quality Assurance in Education, 11(2), pp. 109-113

Park, C., 2003. Levelling the playing field: towards best practice in the doctoral viva. Higher Education Review, 36 (1), pp. 47-67

Remenyi D., Money, A., Price, D. and Bannister, F., 2003. The doctoral viva: a great educational experience of a gun fight at the OK Corral? Irish Journal of Management, 24(2), pp.105-116

Tafford V., 2003. Questions in doctoral vivas; views from the inside. Quality Assurance in Education, 11(2), pp. 114-122

Tinkler, P. and Jackson, C., 2000. Examining the doctorate: institutional policy and the PhD examination process in Britain. Studies in Higher Education , 25(2), pp. 167-180

Wolensky, R P, 1979. Comprehensive examinations and professional development. College Student Journal, 13(3) pp. 28789

\footnotetext{
${ }^{11}$ When I expressed a concern about the fairness of the examination I was told immediately and forcibly that all the University's regulations had been complied with.
} 